\title{
HUBUNGAN MOTIVASI KERJA DENGAN KINERJA PERAWAT DI RUMAH SAKIT UMUM ROYAL PRIMA MEDAN TAHUN 2017
}

\author{
Linda Chiuman ${ }^{1}$, Arlinda Sari Wahyuni ${ }^{2}$, Masnelly Lubis ${ }^{2}$ \\ ${ }^{1}$ Magister Kesehatan Masyarakat, Institut Kesehatan Helvetia, Medan \\ ${ }^{2,3}$ Staf Pengajar Ilmu Kesehatan Masyarakat, Institut Kesehatan Helvetia \\ Email: lqiu_man@yahoo.com
}

\begin{abstract}
Nursing services in hospital healthcare service is one of the crucial factors in defining the image and quality of a hospital. Nurse, a profession which has the highest amount of interaction with the patients and their family, is one of the core elements in determining the quality of healthcare service of a hospital. The purpose of this research is to discover the relation between internal as well as external motivations and the work related performance of the nurses, particularly those who are stationed at the wards in Royal Prima General Hospital Medan. The methodology used analytical study on the survey with cross-sectional approach. The respondents of the survey are all of the nurses who are stationed at the wards with total number of 168 respondents and the sampling method uses proportional random sampling method towards 110 respondents. The data obtained is analyzed with univariate, bivariate methods utilizing chi square as well as multivariate method utilizing double logistic binary regression test analysis with 5\% of confidence interval.The outcome of the research shown that there are relations between internal as well as external motivations and work related performance of the nurses. Nurses with higher value of internal motivations have the chance of 3.061 times to perform better than those with lower value of internal motivations. Additionally, nurses with higher value of external motivations have the chance of 2.761 times to perform better than those with lower value of external motivations. Hence, it is much recommended to the hospital management boards to pay more attention towards the performance of the nurses by considering of giving incentives and rewards to the nurses based on their achievements and loyalty.
\end{abstract}

Keywords: Motivations, Internal Motivations, External Motivations, Performance, Nurses.

\section{PENDAHULUAN}

Pelayanan tenaga kesehatan dalam memberikan pelayanan keperawatan di rumah sakit merupakan salah satu faktor penentu citra dan mutu rumah sakit. Perawat, merupakan kelompok profesi dengan jumlah dan interaksi terbanyak dengan pasien dan keluarga, merupakan salah satu penentu kualitas pelayanan dari rumah sakit yang dinilai dari kinerjanya. Di Namibia (Afrika), kinerja perawat professional yang bekerja di rumah sakit pemerintah dan swasta masih belum dievaluasi sebesar $38,1 \%$. Hal ini menyebabkan upaya peningkatan prestasi kerja dan promosi jabatan belum dijalankan.(1) Di Palestina, perawat yang bekerja di Rumah Sakit Gaza Strip Governmental merasa kurang puas dalam melaksanakan tugas dan tanggung jawabnya sehingga mereka ingin meninggalkan pekerjaannya (30\%).(2) 
Menurut hasil survei dari Persatuan Perawat Nasional Indonesia (PPNI) pada tahun 2006, sekitar 50,9\% perawat yang bekerja di empat provinsi di Indonesia menunjukkan kinerja yang kurang berkualitas yang disebabkan oleh stres akibat kerja, kelelahan, tidak bisa beristirahat karena beban kerja yang terlalu tinggi dan menyita waktu, serta gaji rendah tanpa adanya insentif yang memadai.(3)

Dampak yang terjadi apabila kinerja perawat di rumah sakit yang kurang baik yaitu dapat menyebabkan pasien dan atau keluarga merasa tidak puas, pasien dan atau keluarga tidak akan memanfaaatkan jasa pelayanan kesehatan kembali, dan hal ini akan berdampak pada laba rumah sakit yang akan mengalami penurunan dikarenakan citra rumah sakit yang tidak baik di mata masyarakat.(4)

Permasalahan kinerja perawat merupakan permasalahan mendasar yang akan selalu dijumpai dalam manajemen rumah sakit. Gibson menyatakan bahwa ada tiga faktor yang berpengaruh terhadap kinerja yaitu faktor individu (kemampuan, keterampilan, latar belakang, demografi), faktor psikologis (persepsi, sikap atau attitude, kepribadian atau personality, motivasi dan pembelajaran), dan faktor organisasi (sumber daya, kepemimpinan, penghargaan atau imbalan, struktur organisasi dan desain pekerjaan).(5)
Motivasi sangat penting dalam meningkatkan prestasi kerja atau kinerja seseorang. Motivasi merupakan sebuah dorongan yang merangsang pegawai untuk mencari dan mencapai kepuasan dalam bekerja. Oleh karena itu, diyakini bahwa keseimbangan antara motivasi intrinsik dan ekstrinsik dapat menyebabkan kepuasan dalam bekerja yang lebih besar dan pada gilirannya akan meningkatkan prestasi kerja atau kinerja.(6) Lambrou, dkk menyatakan motivasi perawat di Rumah Sakit Umum Nicosia, Cyprus dipengaruhi oleh faktor insentif finansial dan non finansial.(7) $\mathrm{Di}$ Rumah Sakit Panti Wilasa Citarum Semarang, motivasi perawat masih dikategorikan rendah yaitu sebesar 59,9\%. Prestasi kerja yang diperoleh tidak sesuai dengan harapan karena adanya ketidak rataan dalam pemberian pendidikan atau pelatihan, dan tugas atau pekerjaan.(8)

Beberapa penelitian yang menjelaskan tentang hubungan antara motivasi dengan kinerja perawat yakni penelitian Ayyash yang menunjukkan bahwa tingkat motivasi perawat dalam memberikan pelayanan kesehatan di European Gaza Hospital Palestina adalah sebesar $66,2 \%$ dan proporsi kinerja menurut penilaian tahunan rumah sakit adalah sebesar $82,1 \%$ sehingga dapat disimpulkan bahwa perawat yang bekerja pada umumnya termotivasi 
dalam melaksanakan tugas dan tanggung jawabnya dan mempunyai kinerja yang tinggi.(9) Penelitian serupa oleh Siregar (10), tentang pengaruh motivasi terhadap kinerja perawat pelaksana di ruang rawat inap RSUD Swadana Tarutung Tapanuli Utara, menunjukkan bahwa besarnya pengaruh motivasi (meliputi: prestasi, pengembangan, kondisi kerja, pengakuan, tanggungjawab dan pendapatan) terhadap kinerja perawat pelaksana adalah sebesar $85,7 \%$, sisanya 14,3\% dipengaruhi oleh faktor lain.

Rumah Sakit Umum Royal Prima Medan merupakan salah satu rumah sakit swasta di Kota Medan yang berdiri pada tahun 2014. Rumah sakit ini merupakan rumah sakit kelas B dengan jumlah tempat tidur 200 unit. Untuk menyelenggarakan pelayanan kesehatan di rumah sakit didukung perawat sebanyak 244 orang. Penilaian kinerja rumah sakit berdasarkan nilai Bed Occupancy Rate (BOR) pada tahun 2014 yaitu sebesar 34\%. Pada tahun 2015, Rumah Sakit Umum Royal Prima Medan menjadi salah satu provider BPJS Kesehatan sehingga menyebabkan peningkatan nilai BOR, dari sebesar 29,5\% pada bulan Januari 2015 meningkatkan menjadi sebesar 54,3\% bulan Februari dan terus mengalami peningkatan sekitar $10-15 \%$ sepanjang tahun 2015. Hal ini memberikan dampak langsung kepada kinerja perawat yang merupakan ujung tombak pelayanan kesehatan di rumah sakit.(11)

Ditinjau dari kepuasan pasien, berdasarkan survei terhadap kotak saran didapatkan bahwa $60 \%$ pasien masih tidak puas terhadap pelayanan keperawatan di Rumah Sakit Umum Royal Prima Medan. Ketidakpuasan yang dirasakan terutama berupa respon perawat terhadap keluhan yang lambat, perawat yang kurang ramah, dan komunikasi perawat yang kurang efektif. Hal ini mengindikasikan bahwa kinerja perawat masih belum maksimal dan disebabkan oleh motivasi kerja perawat yang masih rendah. Upaya yang telah dilakukan oleh Rumah Sakit Umum Royal Prima Medan secara organisasi dalam rangka meningkatkan kinerja perawat adalah dengan memberikan kesempatan kepada perawat untuk melanjutkan pendidikan dan pelatihan secara bergantian dan mengikuti seminar dan pelatihan sesuai jadwal kerja, namun kinerja perawat masih dinilai rendah. Berdasarkan latar belakang di atas, maka peneliti tertarik untuk meneliti hubungan antara motivasi dengan kinerja perawat pelaksana di ruang rawat inap Rumah Sakit Umum Royal Prima Medan.

Tujuan penelitian adalah untuk mengetahui hubungan motivasi (internal dan eksternal) dengan kinerja perawat pelaksana di ruang rawat inap Rumah Sakit Umum Royal Prima Medan. 
METODE

Metode penelitian berupa survei analitik dengan pendekatan cross sectional. Penelitian dilaksanakan di Rumah Sakit Umum Royal Prima Medan pada bulan Februari-April 2017. Populasi penelitian adalah seluruh perawat pelaksana ruang rawat inap yang berjumlah 168 orang dan pengambilan sampel dengan menggunakan metode propotional random sampling yaitu sebanyak 110 orang. Pengumpulan data dilakukan dengan menggunakan kuesioner dan dokumen/laporan yang berhubungan dengan rumah sakit.

Pengolahan data dilakukan dengan menggunakan program SPSS. Dan data dianalisis secara univariat, bivariat denagn menggunakan chi square dan multivariat dengan menggunakan analisis uji regresi logistik berganda dengan tingkat kemaknaan 5\%.

Data dianalisis secara univariat, bivariat dengan

\section{HASIL DAN PEMBAHASAN}

\section{Hasil}

\section{Analisis Univariat}

\section{Karakteristik Perawat}

Perawat pelaksana yang bekerja di ruang rawat inap sebagian besar berumur diantara 23-32 tahun yaitu sebanyak 69 orang $(62,7 \%)$, berjenis kelamin perempuan sebanyak 94 orang $(85,5 \%)$, tamatan pendidikan S1 sebanyak 58 orang $(52,7 \%)$, pernah mengikuti pelatihan yang diselenggarakan oleh rumah sakit sebanyak 78 orang $(70,9 \%)$ dan berstatus menikah sebanyak 84 orang $(76,4 \%)$.

\section{Motivasi \\ Variabel motivasi yang diteliti terdiri dari motivasi internal dan motivasi eksternal.}

\section{Motivasi Internal}

Distribusi frekuensi jawaban perawat tentang motivasi internal sebagian besar dikategorikan memiliki motivasi internal yang rendah sebanyak 56 orang $(50,9 \%)$, dan selebihnya memiliki motivasi internal yang tinggi sebanyak 54 orang $(49,1 \%)$.

\section{Motivasi Eksternal}

Distribusi frekuensi jawaban perawat tentang motivasi eksternal sebagian besar dikategorikan memiliki motivasi eksternal yang tinggi sebanyak 61 orang $(55,5 \%)$, dan selebihnya memiliki motivasi eksternal yang rendah sebanyak 49 orang $(44,5 \%)$.

\section{Kinerja Perawat}

Distribusi frekuensi jawaban perawat tentang kinerja dalam memberikan pelayanan kesehatan sebagian besar dikategorikan memiliki kinerja yang baik sebanyak 59 orang $(53,6 \%)$, dan selebihnya memiliki kinerja yang tidak baik sebanyak 51 orang $(46,4 \%)$. 
Analisis Bivariat

Hubungan Motivasi Internal dengan

Kinerja Perawat

Tabel 1.

Hubungan Motivasi Internal dengan

Kinerja Perawat

\begin{tabular}{|c|c|c|c|c|c|c|c|c|}
\hline \multirow{3}{*}{$\begin{array}{l}\text { Motivasi } \\
\text { Internal }\end{array}$} & \multicolumn{4}{|c|}{$\begin{array}{l}\text { Kinerja } \\
\text { Perawat }\end{array}$} & \multirow{2}{*}{\multicolumn{2}{|c|}{ Total }} & \multirow{2}{*}{$\chi^{2}$} & \multirow[b]{2}{*}{$\mathbf{p}$} \\
\hline & \multicolumn{2}{|c|}{ Baik } & \multicolumn{2}{|c|}{$\begin{array}{l}\text { Tidak } \\
\text { Baik }\end{array}$} & & & & \\
\hline & n & $\%$ & $\mathrm{n}$ & $\%$ & $\mathrm{n}$ & $\%$ & & \\
\hline Tinggi & 36 & 66,7 & 18 & 33,3 & 54 & 100 & & \\
\hline Rendah & 23 & 41,1 & 33 & 58,9 & 56 & 100 & 7,242 & $\begin{array}{l}0,01 \\
2\end{array}$ \\
\hline
\end{tabular}

Tabel 1 menunjukkan bahwa perawat yang mempunyai motivasi internal yang tinggi sebanyak 54 orang, sebagian besar mempunyai kinerja yang baik dalam melaksanakan asuhan keperawatan yaitu sebanyak 36 orang $(66,7 \%)$. Perawat yang mempunyai motivasi internal yang rendah sebanyak 56 orang, sebagian besar mempunyai kinerja yang tidak baik dalam melaksanakan asuhan keperawatan yaitu sebanyak 33 orang (58,9\%). Hasil uji statistik chi square diperoleh nilai $\chi_{\text {hitung }}^{2} 7,242>\chi_{\text {tabel (dk=k-1) }}^{2} 3,84$ dan nilai probabilitas $0,012<0,05$. Hal ini berarti ada hubungan antara motivasi internal dengan kinerja perawat.

Hubungan Motivasi Eksternal dengan Kinerja Perawat

Tabel 2.

Hubungan Motivasi Eksternal dengan Kinerja Perawat

\begin{tabular}{|c|c|c|c|c|c|c|c|c|}
\hline \multirow{3}{*}{$\begin{array}{l}\text { Motivasi } \\
\text { Ekster- } \\
\text { nal }\end{array}$} & \multicolumn{4}{|c|}{$\begin{array}{l}\text { Kinerja } \\
\text { Perawat }\end{array}$} & \multirow{2}{*}{\multicolumn{2}{|c|}{ Total }} & \multirow{3}{*}{$\chi^{2}$} & \\
\hline & \multicolumn{2}{|c|}{ Baik } & \multicolumn{2}{|c|}{$\begin{array}{l}\text { Tidak } \\
\text { Baik }\end{array}$} & & & & \\
\hline & $\mathbf{n}$ & $\%$ & $\mathbf{n}$ & $\%$ & $\mathrm{n}$ & $\%$ & & \\
\hline Tin & 39 & 63,9 & 22 & 36,1 & 61 & 100 & & \\
\hline Rendah & 20 & 40,8 & 29 & 59,2 & 49 & 100 & 5,840 & 0,02 \\
\hline
\end{tabular}

Tabel 2 menjelaskan bahwa perawat yang mempunyai motivasi eksternal yang tinggi sebanyak 61 orang, sebagian besar mempunyai kinerja yang baik dalam melaksanakan asuhan keperawatan yaitu sebanyak 39 orang $(63,9 \%)$. Perawat yang mempunyai motivasi eksternal yang rendah sebanyak 49 orang, sebagian besar mempunyai kinerja yang tidak baik dalam melaksanakan asuhan keperawatan yaitu sebanyak 29 orang $(59,2 \%)$ Hasil uji statistik chi square diperoleh nilai $\chi_{\text {hitung }}^{2} 5,840>\chi_{\text {tabel (dk=k-1) }}^{2} 3,84$ dan nilai probabilitas $0,026<0,05$. Hal ini berarti ada hubungan antara motivasi eksternal dengan kinerja perawat.

\section{Analisis Multivariat}

Tabel 3.

Pengaruh Motivasi (Internal dan Eksternal) terhadap Kinerja Perawat

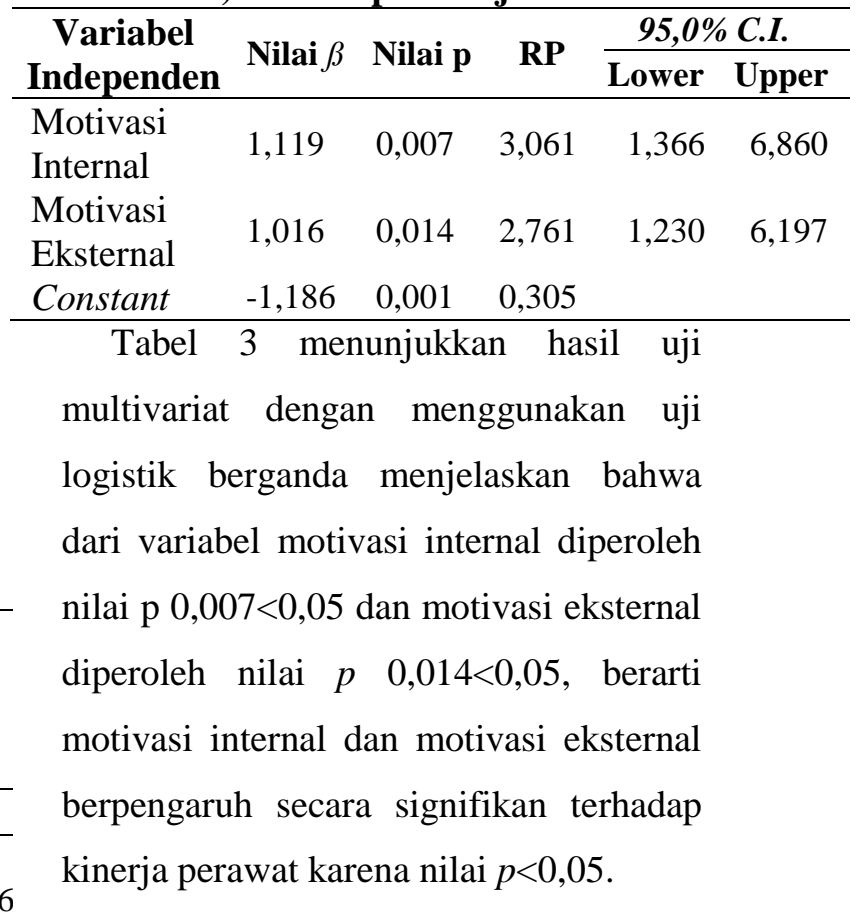


Nilai Prevalance Ratio variabel motivasi internal sebesar 3,061, 95\% CI: $1,366-6,860$, berarti perawat yang mempunyai motivasi internal yang tinggi berpeluang 3,061 kali berkinerja baik daripada perawat yang mempunyai motivasi internal yang rendah. Nilai Prevalance Ratio variabel motivasi eksternal sebesar 2,761, 95\% CI: 1,2306,197. Hal ini berarti perawat yang mempunyai motivasi eksternal yang tinggi berpeluang 2,761 kali berkinerja baik daripada perawat yang mempunyai motivasi eksternal yang rendah. Variabel motivasi internal sebagai faktor dominan yang mempengaruhi kinerja perawat.

\section{Pembahasan}

\section{Pengaruh Motivasi terhadap Kinerja Perawat}

Hasil penelitian menunjukkan bahwa para perawat pelaksana ruang rawat inap dalam memberikan pelayanan keperawatan sebagian besar mempunyai motivasi internal yang dikategorikan rendah yaitu sebesar 50,9\%, dan selebihnya dikategorikan mempunyai motivasi internal yang tinggi yaitu sebesar $49,1 \%$. Sedangkan dalam hal motivasi eksternal, para perawat pelaksana ruang rawat inap dalam memberikan pelayanan keperawatan sebagian besar mempunyai motivasi eksternal yang dikategorikan tinggi yaitu sebesar 55,5\%, dan selebihnya dikategorikan mempunyai motivasi eskternal yang rendah dalam mendukung pelayanan keperawatan yaitu sebesar $44,5 \%$.

Berdasarkan hasil uji statistik chi square menunjukkan bahwa ada hubungan antara motivasi internal $\left(\chi_{\text {hitung }}^{2}\right.$ 7,242> $\chi_{\text {tabel (dk=k-1) 3,84) dan motivasi }}^{2}$ eksternal $\quad \chi_{\text {hitung }}^{2} 5,840>\chi_{\text {tabel }}^{2} \quad(\mathrm{dk}=\mathrm{k}-1)$ $3,84)$ dengan kinerja perawat. Hasil ini sejalan dengan penelitian yang dilakukan oleh Aryandini di Rumah Sakit PKU Muhammadiyah Yogyakarta yang menyatakan bahwa ada hubungan yang signifikan antara motivasi internal dan eksternal dengan kinerja perawat.(12)

Berdasarkan hasil uji statistik regresi logistik berganda diperoleh hasil bahwa motivasi internal $(\mathrm{p} 0,007)$ dan motivasi ekternal (p 0,014) berpengaruh terhadap kinerja perawat. Hasil ini sejalan dengan hasil penelitian yang dilakukan oleh Lingga di Rumah Sakit Umum Ferdinand L. Tobing di Sibolga yang menyatakan bahwa motivasi berpengaruh signifikan terhadap kinerja perawat pelaksana dengan hasil penelitian $p 0,0001(p<0,05)$ khususnya motivasi instrinsik dan motivasi ekstrinsik.(13) Hasil uji statistik regresi logistik berganda dengan metode Enter didapatkan nilai overall percentage sebesar $63,6 \%$, yang berarti bahwa model regresi logistik yang digunakan sudah cukup baik karena mampu memprediksi dengan benar $63,6 \%$ kondisi yang terjadi. 
Pengaruh Motivasi Internal terhadap Kinerja Perawat

Berdasarkan hasil uji statistik regresi logistik berganda menunjukkan bahwa motivasi internal berpengaruh terhadap kinerja perawat di Rumah Sakit Umum Royal Prima Medan (p 0,007<0,05) Penelitian serupa dilakukan oleh Aryandini yang meneliti aspek motivasi internal paling banyak mempengaruhi tingkat kinerja perawat adalah aspek prestasi, aspek tanggung jawab, aspek pengalaman kerja, aspek pengakuan dan aspek perkembangan yang menunjukkan bahwa ada hubungan yang signifikan antara motivasi kerja dengan tingkat kinerja perawat $(p<0,05) .(12)$ Hasil penelitian ini juga didukung oleh penelitian Siregar dimana hasil penelitiannya menyatakan bahwa variabel motivasi intrinsik yang mempunyai pengaruh yang dominan dan signifikan terhadap kepuasan kerja yang akan mempengaruhi kinerja perawat pelaksana di instalasi rawat inap pada Rumah Sakit Umum Pusat Haji Adam Malik Medan adalah prestasi dan pekerjaan itu sendiri.(10)

Berdasarkan hasil penelitian diperoleh nilai $P R$ sebesar 3,061, 95\% CI: $1,366-$ 6,860. Hal ini berarti perawat pelaksana yang mempunyai motivasi yang bersumber dari dalam dirinya yang tinggi berpeluang 3,061 kali berkinerja baik daripada perawat pelaksana yang mempunyai motivasi internal rendah.
Walaupun hasil penelitian menjelaskan kinerja perawat pelaksana sudah baik, tetapi masih ditemukan kinerja yang tidak baik sebesar 46,4\%. Motivasi internal merupakan variabel yang dominan yang mempengaruhi kinerja perawat dibandingkan motivasi eksternal disebabkan perawat dalam bekerja walaupun didukung manajemen yang baik, fasilitas, dan peralatan yang memadai, tetapi jika mereka kurang bergairah, lekas bosan, dan stress akan menurunkan kinerja juga. Hal penting dalam motivasi internal adalah keinginan perawat untuk menjadi pemberi pelayanan kesehatan yang profesional harus didukung dengan kegiatan pelatihan secara berkelanjutan yang diselenggarakan oleh rumah sakit agar dapat meningkatkan motivasi untuk meningkatkan kepuasan bekerja sekaligus meningkatkan kinerja rumah sakit.

\section{Pengaruh Motivasi Eksternal terhadap Kinerja Perawat}

Berdasarkan hasil uji statistik regresi logistik berganda menunjukkan bahwa motivasi eksternal berpengaruh secara signifikan terhadap kinerja perawat di Rumah Sakit Umum Royal Prima Medan dengan nilai $p \quad 0,014<0,05$. Sejalan dengan penelitian Lingga yang menyatakan bahwa motivasi ( $p 0,0001)$ dan kompetensi $(p 0,0001)$ berpengaruh signifikan terhadap kinerja perawat. 
Lingga menilai motivasi berdasarkan motivasi ekstrinsik yang terdiri dari insentif, kondisi kerja, hubungan kerja dan prosedur kerja.(13) Penelitian ini juga sejalan dengan penelitian Sabarulin yang menggunakan jenis penelitian survei analitik dengan rancangan cross sectional di Rumah Sakit Woodward Palu yang menunjukkan bahwa ada pengaruh motivasi terhadap kinerja perawat dengan nilai $\mathrm{p}$ 0,001, ada pengaruh kepemimpinan terhadap kinerja perawat dengan nilai $\mathrm{p} 0,003$, dan ada pengaruh imbalan terhadap kinerja perawat dengan nilai p 0,018. Faktor yang paling berpengaruh terhadap kinerja perawat adalah motivasi dengan nilai Exp (B) $=0,089 .(14)$

Semakin baik motivasi seorang perawat akan dapat meningkatkan kinerjanya dalam memberikan pelayanan kesehatan kepada pasien. Danuarta menyatakan bahwa, faktor yang mempengaruhi pencapaian kinerja adalah faktor kemampuan (ability) dan faktor motivasi (motivation).(15) Sedangkan menurut Keith Davis dalam Mangkunegara dirumuskan bahwa faktor-faktor yang dapat mempengaruhi kinerja adalah : Human Performance = Ability + Motivation; Motivation = Attitude + Situation; Ability = Knowledge + Skill.(16)

Menurut Sutrisno, motivasi sebagai proses psikologi dalam diri seseorang dapat dipengaruhi hal-hal yang berasal dari luar diri pegawai seperti lingkungan, kompensasi, supervisi, jaminan kesehatan dan tanggung jawab.(17) Berdasarkan hasil penelitian orang lain dan pendapat para ahli menjelaskan bahwa motivasi eskternal perawat berkaitan dengan kinerja dalam memberikan pelayanan asuhan keperawatan.

Hasil penelitian, didapatkan nilai $P R$ sebesar 2,761. Hal ini berarti bahwa perawat pelaksana yang mempunyai motivasi yang bersumber dari luar dirinya yang tinggi berpeluang 2,761 kali berkinerja baik daripada perawat pelaksana yang mempunyai motivasi eksternal yang rendah. Berdasarkan jawaban perawat di atas, maka motivasi eksternal perawat pelaksana dapat dikelompokkan dalam kategori tinggi yaitu sebesar $55,5 \%$. Hal ini disebabkan rumah sakit memiliki komitmen untuk meningkatkan citra rumah sakit yaitu menjadi rumah sakit yang memberikan pelayanan kesehatan terbaik, standar kualitas tinggi serta memenuhi kebutuhan pasien dan keluarga pasien. Rumah sakit berupaya melengkapi segala peralatan dan meningkatkan fasilitas serta selalu memperbaharui peraturan yang ada agar bisa memberikan kenyamanan kepada para pegawai dalam memberikan pelayanan kesehatan. 
Hasil penelitian juga menunjukkan dukungan motivasi eksternal kepada perawat dalam meningkatkan pelayanan asuhan keperawatan rendah sebesar 44,5\%. Hal ini disebabkan kegiatan pelatihan dan sosialisasi SOP tidak dilaksanakan secara kontiniu, pemberian insentif tidak dibudidayakan, penggajian belum sesuai dengan masa kerja perawat, dan jaminan masa tua perlu dipertimbangkan sebagai bukti bahwa rumah sakit memiliki komitmen meningkatkan kualtias layanan asuhan keperawatan.

Motivasi eksternal yang diberikan rumah sakit yang tinggi tentunya dapat meningkatkan dorongan atau keinginan perawat bekerja lebih giat lagi. Sebaliknya motivasi eksternal yang diberikan rumah sakit yang rendah atau kurang mendukung dapat menurunkan semangat atau keinginan perawat bekerja lebih giat.

Proporsi kinerja perawat memang tergolong sudah baik yaitu sebesar $53,6 \%$, mungkin disebabkan latar belakang perawat lebih banyak tamatan Sarjana Keperawatan dari pada Diploma III Keperawatan. Latar belakang pendidikan perawat yang tinggi akan cenderung memiliki kinerja yang tinggi. Disamping itu, masa kerja perawat di atas 2 tahun dapat menjadi pengalaman dalam memberikan pelayanan asuhan keperawatan yang bermutu.
Di masa mendatang motivasi eksternal perlu dipertahankan dan ditingkatkan oleh pimpinan rumah sakit dengan menyelenggarakan pelatihan, workshop, dan sosialisasi SOP secara berkala. Selain itu, kepala ruangan juga dapat menyelenggarakan diskusi refleksi kasus, dimana pengalaman klinis perawat yang direfleksikan merupakan pengalaman aktual dan menarik baik halhal yang merupakan keberhasilan maupun kegagalan dalam memberikan pelayanan keperawatan untuk menemukan masalah dan menetapkan upaya penyelesaian masalah keperawatan minimal satu bulan sekali dengan tujuan untuk mengembangkan profesionalisme perawat.

\section{KESIMPULAN DAN SARAN}

\section{Kesimpulan}

1. Perawat pelaksana ruang rawat inap Rumah Sakit Umum Royal Prima mempunyai motivasi internal yang dikategorikan rendah yaitu sebesar 50,9\% namun mempunyai motivasi eksternal yang dikategorikan tinggi yaitu sebesar 55,5\%.

2. Perawat pelaksana ruang rawat inap Rumah Sakit Umum Royal Prima mempunyai kinerja yang dikategorikan baik yaitu sebesar $53,6 \%$.

3. Hasil uji statistik chi square menunjukkan bahwa ada hubungan 
antara motivasi internal $\left(\chi^{2}\right.$ hitung 7,242> $\left.\quad \chi_{\text {tabel }}^{2} \quad(\mathrm{dk}=\mathrm{k}-1) \quad 3,84\right) \quad$ dan motivasi eksternal ( $\chi_{\text {hitung }}^{2} 5,840>$

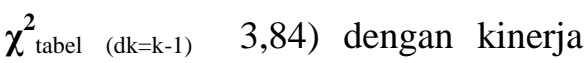
perawat pelaksana di ruang rawat inap Rumah Sakit Umum Royal Prima Medan.

4. Perawat pelaksana ruang rawat inap yang mempunyai motivasi internal yang tinggi dan mempunyai kinerja yang baik dalam melaksanakan pelayanan keperawatan yaitu sebesar $66,7 \%$. Sedangkan perawat yang mempunyai motivasi internal yang rendah dan mempunyai kinerja yang tidak baik dalam melaksanakan pelayanan keperawatan yaitu sebesar $58,9 \%$.

5. Hasil uji statistik regresi logistik berganda menunjukan bahwa ada pengaruh motivasi internal ( $p$ 0.007) dan motivasi eksternal (p 0.014) terhadap kinerja perawat pelaksana ruang rawat inap Rumah Sakit Umum Royal Prima Medan.

6. Motivasi internal mempunyai nilai $P R$ sebesar 3,061. Hal ini berarti perawat pelaksana ruang rawat inap yang mempunyai motiviasi internal yang tinggi berpeluang 3,061 kali berkinerja baik dibandingkan perawat pelaksana ruang rawat inap yang mempunyai motivasi internal yang rendah.
7. Motivasi eksternal mempunyai nilai $P R$ sebesar 2,761. Hal ini berarti perawat pelaksana ruang rawat inap yang mempunyai motiviasi eksternal yang tinggi berpeluang 2,761 kali berkinerja baik dibandingkan perawat pelaksana ruang rawat inap yang mempunyai motivasi eksternal yang rendah.

\section{Saran}

1. Rumah Sakit Royal Prima Medan

a. Pimpinan rumah sakit mempertimbangkan pemberian insentif dan reward kepada perawat berdasarkan prestasi kerja dan masa kerja dan lebih aktif menyelenggarakan pelatihan, workshop, dan sosialisasi dalam rangka meningkatkan ilmu pengetahuan (knowledge), ketrampilan (skills) dan sikap (attitude) terutama mengenai soft skills agar bisa memotivasi para perawat pelaksana.

b. Rumah sakit melakukan sosialisasi mengenai perlengkapan dan fasilitas yang ada serta cara penggunaannya dan menyelenggarakan family gathering atau outbound seluruh staf secara berkala beberapa bulan sekali agar bisa tercipta hubungan yang harmonis antar 
staf dan dengan atasan di rumah sakit.

\section{Kepala Ruangan}

a. Kepala ruangan lebih terbuka dan menghargai ide atau saran dari perawat pelaksana dan memperhatikan hasil kinerja perawat pelaksana dan memberikan pujian terhadap hasil kerja yang bagus agar dapat memotivasi para perawat pelaksana untuk bisa bekerja lebih giat lagi.

b. Melakukan diskusi refleksi kasus dan mempresentasikan hasil pelatihan untuk berbagi pengalaman antar perawat.

3. Perawat

Diharapkan para perawat pelaksana dapat meningkatkan kemampuan, keterampilan, dan sikap sehingga bisa menjadi perawat yang profesional sekaligus terdorong melakukan pelayanan keperawatan dengan lebih baik lagi, mulai dari pengkajian, diagnosa, perencanaan, tindakan dan evaluasi keperawatan.

\section{DAFTAR PUSTAKA}

1. Awases M.H., Bezuidenhout M.C. \& Roos J.H. Factors affecting the performance of professional nurses in Namibia, Curationis; 2013. 36 (1).

2. Tabeel, Baha Eldin Ahmed. Motivation and Job Performance among Nurses in Gaza Strip
Governmental Hospitals - Palestine; 2014.

3. Nursalam. Manajemen Keperawatan Aplikasi Dalam Praktik Keperawatan Profesional Edisi 4. Jakarta : Salemba Medika; 2014.

4. Khamida M. Kinerja Perawat Dalam Memberikan Asuhan Keperawatan Berpengaruh Terhadap Kepuasan Pasien Rawat Inap. Jurnal Ilmiah Kesehatan; 2015. Vol. 8 (2): 154161.

5. Gibson J.L. Struktur Organisasi dan Manajemen. Jakarta: Erlangga 5; 2003.

6. Hee, Ong Choon. Motivation and Job Performance among Nurses in the Private Hospitals in Malaysia. International Journal of Caring Sciences January - April 2016 Volume 9 | Issue 1| Page 342.

7. Lambrou P. Motivation and job satisfaction among medical and nursing staff in a Cyprus public general hospital. National Center for Biotechnology Information; 2010. U.S. National Library of Medicine. https://www.ncbi. nlm.nih. gov/pmc/articles/PMC2998451/.

8. Hasmoko, Emanuel V. Analisis Faktor-Faktor Yang Mempengaruhi Kinerja Klinis Perawat Berdasarkan Penerapan Sistem Pengembangan Manajemen Kinerja Klinis (SPMKK) di Ruang Rawat Inap Rumah Sakit Panti Wilasa Citarum Semarang; 2008. Tesis, Program Pascasarjana Universitas Diponegoro.

9. Ayyash, Hala. Nurses' Motivation and their Performance at European Gaza Hospital in Gaza Strip. Journal of Al Azhar University-Gaza (Natural Sciences), 2011, 13:55-68.

10. Siregar M. Pengaruh Motivasi Terhadap Kinerja Perawat Pelaksana di Ruang Rawat Inap RSUD Swadana Tarutung Tapanuli Utara. Medan; 2008. Tesis. Sekolah Pascasarjana USU.

11. RSU Royal Prima. Laporan Evaluasi Rumah Sakit Royal Prima. Medan; 2016. 
12. Aryandini E. Hubungan antara Motivasi Kerja Perawat dengan Tingkat Kinerja Perawat di Ruang Instalasi Kegawatdaruratan RS PKU Muhammadiyah Yogyakarta. 2015.

13. Lingga JH. Pengaruh Motivasi dan Kompetensi terhadap Kinerja Perawat Pelaksana di RSU dr. Ferdinand Lumban Tobing Sibolga. Medan; 2012. FKM USU.

14. Sabarulin. Faktor Yang Mempengaruhi Kinerja Perawat Dalam Mendokumentasikan Asuhan Keperawatan di Rumah Sakit Woodward Palu. 2013

15. Sastrohadiwiryo, B. S. Manajemen Tenaga Kerja Indonesia, Jakarta: Bumi Aksara; 2003.

16. Mangkunegara AA.A. P. Evaluasi Kinerja SDM. Bandung: Refika Aditama. 2013.

17. Sutrisno E. Manajemen Sumber Daya Manusia, Kencana Prenada Media Group, Jakarta. 2010. 